\title{
A Simple Idea on the Unification of Einstein-Bohr Controversy
}

\author{
Wei-Cheng Cui ${ }^{1,2 *}$ \\ ${ }^{1}$ School of Engineering, Westlake University, China \\ ${ }^{2}$ Shanghai Engineering Research Center of Hadal Science and Technology, Shanghai Ocean University, China
}

Submission: January 23, 2019; Published: January 30, 2019

"Corresponding author: Wei-Cheng Cui, Chair professor at Westlake University, China and adjunct professor at Shanghai Ocean University, China

\begin{abstract}
Whether the world works regularly or not, and whether the nature of the world is knowable or unknowable, Einstein and Bohr have debated these two questions for more than 40 years and even up to now, physicists continue the debate. From my point of view, this controversy was created by Bohr's over claim. The purpose of this short note is to present my simple idea of unification of Einstein-Bohr controversy.
\end{abstract}

Keywords: Einstein-Bohr controversy; Unification; Knowability; Agnosticism

\section{Opinion}

Whether the world works regularly or not, and whether the nature of the world is knowable or unknowable, Einstein and Bohr have debated these two questions for more than 40 years, no one was persuaded by the other until their death. After that, physicists divided into two camps to continue the debate. The detailed story can be found in many articles and books, e.g. [1,2].

I find Bohr's agnosticism a paradox in its own way. If he was believed that the operation of the micro world is irregular and the nature of the micro world is unknowable, then he should stop to carry out research to seek the statistical operation law of the micro world. The law of statistics is also a law of operation. In addition, just because he did not know himself at that time, there was no need to make the claim that other people did not know, and it cannot be known by others in the future. Furthermore, if he thought only the operation of the macro world is regular, then he needed to define a clear boundary between macro world and micro world. I think he would be difficult to justify why there is a sudden jump at this boundary if he really creates an artificial boundary between the two worlds.

Therefore, the basic idea of my unification of Einstein-Bohr controversy is very simple. Philosophically, we believe that (1) the universe including macro and micro worlds always works regularly or with rules, and (2) these rules can always be revealed by us humans. The fundamental task of our scientific research is to reveal these rules.

One universal method of revealing how the world works is the general system theory (GST) [3,4]. Regarding any object to be studied as a system, any system includes five elements, namely, the system itself, constraint conditions, boundary support condi tions, input and output. Given the system, constraints and boundary support conditions, the output will be a function of the input, and the function $\mathrm{f}$ is called the transfer function. This function can always be revealed by us humans either accurately or approximately. The general format of the transfer function can be expressed as follows:

$$
Y=f\left(x_{1}, x_{2}, \ldots, x n\right)
$$

where $\mathrm{Y}$ is the property we are interested in and $\mathrm{x} 1, \mathrm{x} 2, \ldots, \mathrm{xn}$, are the factors which affect the value of Y.

However, due to the complexity of the actual system and the time limit of our human life, we may not be able to reveal the real rules of the system operation in our lifetime, especially it is hard for us to identify all the influencing factors. For example, even for the fatigue life of a standard specimen such as tension of a round steel bar under the constant amplitude loading, the fatigue life $\mathrm{N}$ would be a function of fatigue loading $\left(\sigma_{\text {max }^{\prime}} \Delta \sigma\right)$, specimen manufacturing quality (initial crack size $\mathrm{a}_{0}$ ), final crack size $\left(\mathrm{a}_{\mathrm{f}}\right)$, material manufacturing quality partly reflected in material properties (such as Yield strength $\sigma_{\mathrm{y}^{\prime}}$ Young's modulus E, Ultimate strength $\sigma_{u}$ ). At the moment, the linear cumulative damage theory is the dominant theory used in various industries which ignores the influences of specimen manufacturing quality (initial crack size $\left.\mathrm{a}_{0}\right)$ and final crack size $\left(\mathrm{a}_{\mathrm{f}}\right)$, and only take the load amplitude into consideration, the fatigue life for a particular so-called qualified specimen cannot be predicted accurately and the scatter can be more than one order of magnitude [5]. Even for the more accurate theory based on fracture mechanics, all the factors related to human beings are hardly considered although these factors have been found to be important in some occasions. 
If all the influencing factors have not been identified in Eq. (1), then the transfer function is an approximate format. We can define those ignored factors as hidden variables. Because of the existence of hidden variables and the approximate nature of the transfer function, there is no one to one correspondence between $X$ vector and $Y$ value in Eq. (1), and the system is uncertain. In this case, any theory handling uncertainty such as probability and statistics can be applied.

In conclusion, for systems with no hidden variables, the transfer function may be given precisely using deterministic mathematics. For systems with hidden variables, the mathematics with uncertainty, such as the theory of probability and statistics, can be applied. There is no inconsistency to be debated. The deepening research can be carried out in two directions. One is to study the mechanism more precisely and reduce or eliminate hidden variables. The second is to study its application. On the premise of only considering the currently accepted explicit influencing factors, probability and statistics theory is applied to improve the reliability of prediction as much as possible under the condition of existing information or collecting more information only on these factors. Philosophically speaking, there is no need to make the claims that (1) there is no rule in the micro world operation and (2) there exists irreducible uncertainty or objective uncertainty.

\section{References}

1. Whitaker, A (2006) Einstein, Bohr and the Quantum Dilemma - From Quantum Theory to Quantum Information, ( $2^{\text {nd }}$ edn), Paperback, Cambridge University Press, UK.

2. Cui, WC, Kang, BL (2008) Examining the debate between Einstein and Bohr based on Buddhist philosophy. Journal of Chinese Social Sciences 55(8): 1-9.

3. Bertalanffy, LV (1968) General System Theory: Foundations, Development, Applications, George Braziller, New York, USA.

4. Chen, D, Stroup, W (1993) General System Theory: Toward a Conceptual Framework for Science and Technology Education for All. Journal of Science Education and Technology 2(7): 447-459.

5. Cui, WC, Huang, XP, Wang (2013) Towards a Unified Fatigue Life Prediction Method for Marine Structures, Zhejiang University Press and Springer, USA.

This work is licensed under Creative 